\title{
Haemotoxic snakebite in rural KwaZulu-Natal, South Africa: A case presenting with haematemesis
}

\author{
M Wagener \\ Mark Wagener, MB ChB (University of Cape Town), is a medical officer grade 1 in General Surgery at Ngwelezane Hospital, Empangeni, \\ KwaZulu-Natal, South Africa.
}

Corresponding author: M Wagener (mark.wagener2@gmail.com)

\begin{abstract}
A 36-year-old man who had been bitten on the left index finger by a snake identified as a boomslang (Dispholidus typus) presented with haematemesis and hypovolaemic shock. Coagulopathy was presumed, and the platelet count was $2 \times 10^{9} / \mathrm{L}$. Findings on upper endoscopy included oesophageal petechial haemorrhages, severe haemorrhagic gastritis and an antral ulcer. The patient was successfully managed using freeze-dried plasma, packed red blood cells, isotonic crystalloids and polyvalent antivenom.
\end{abstract}

S Afr Med J 2016;106(5):459-460. DOI:10.7196/SAMJ.2016.v106i5.9124

\section{Case report}

A 36-year-old man sustained a snakebite on the left index finger at $17 \mathrm{~h} 00$. The snake was caught and identified as a boomslang (Dispholidus typus) according to the referring doctor. He presented to his local district hospital at midnight, was referred to Ngwelezane Hospital (Empangeni, KwaZulu-Natal, South Africa) and arrived there at $07 \mathrm{~h} 00$ the next day.

The patient had developed haematemesis from $01 \mathrm{~h} 00$ while at the base hospital, active haematemesis being witnessed by medical staff. He also had painful progressive swelling of the left arm. There was no past medical history of note, and his HIV status was unknown. He had no history of non-steroidal anti-inflammatory use, but admitted to excessive alcohol intake.

On examination at the base hospital, the patient's pulse rate was $100 / \mathrm{min}$ and his blood pressure $86 / 50 \mathrm{mmHg}$. He was dehydrated and pale, was not jaundiced and had no signs of chronic liver disease. There was swelling of the left arm from the fingertips to above the elbow. The

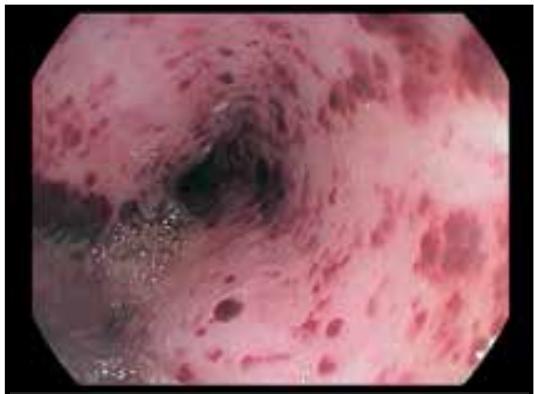

Fig. 1. Endoscopic view of the oesophagus of a patient with haemotoxic snakebite, demonstrating diffuse petechial haemorrhages. compartments were not tense and there was no area of skin necrosis. Examination of the respiratory and cardiovascular systems revealed no other abnormalities, and the patient was alert and orientated.

Details of resuscitation initiated at the base hospital were as follows. The patient's airway was self-maintained before, during and after administration of antivenom, the lungs had equal air entry, and he did not develop bronchospasm before, during or after administration of antivenom. Because circulatory changes showed evidence of hypovolaemic shock on presentation, two 18-gauge intravenous (IV) cannulas were inserted and he was given a total of $3 \mathrm{~L}$ normal saline, $3 \times 500 \mathrm{~mL}$ units of freshdried plasma (FDP) given empirically for presumed coagulopathy, and a $40 \mathrm{mg}$ IV bolus of pantoprozole.

Polyvalent antivenom (four $10 \mathrm{~mL}$ ampoules, i.e. $40 \mathrm{~mL}$ ) in $200 \mathrm{~mL}$ normal saline was administered over 15 minutes, preceded by $0.5 \mathrm{~mL} \mathrm{1:1} 000$ adrenaline as an intramuscular injection (IMI), $25 \mathrm{mg}$ promethazine as an IMI, and $200 \mathrm{mg}$

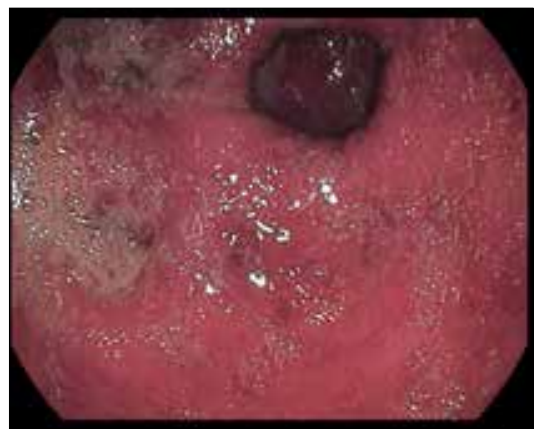

Fig. 2. View of the stomach looking towards the antrum, showing severe gastritis. hydrocortisone as an IMI. The patient did not develop any evidence of anaphylaxis after administration of antivenom.

He was also given one unit of packed red blood cells.

The results of testing of blood samples taken before resuscitation and referral were as follows: sodium $127 \mathrm{mmol} / \mathrm{L}$, potassium $3.6 \mathrm{mmol} / \mathrm{L}$, chloride $100 \mathrm{mmol} / \mathrm{L}$, urea $7.5 \mathrm{mmol} / \mathrm{L}$, creatinine $111 \mathrm{mmol} / \mathrm{L}$, haemoglobin $(\mathrm{Hb}) 11.1 \mathrm{~g} / \mathrm{dL}$, platelets $2 \times 10^{9} / \mathrm{L}$ and international normalised ratio (INR) 0.96 .

On arrival at Ngwelezane Hospital, the patient was still alert and orientated. His pulse rate was $94 / \mathrm{min}$ and his blood pressure $142 / 72 \mathrm{mmHg}$. The swelling of the left arm from fingertips to above the elbow had not progressed beyond where it had been marked by the doctor at the base hospital.

The patient underwent gastroscopy at Ngwelezane Hospital at 09h00, performed by the author. The findings were as follows: oesophagus - diffuse petechial haemorrhages (Fig. 1); stomach - severe diffuse gastritis (Fig. 2) and a prepyloric ulcer with overlying

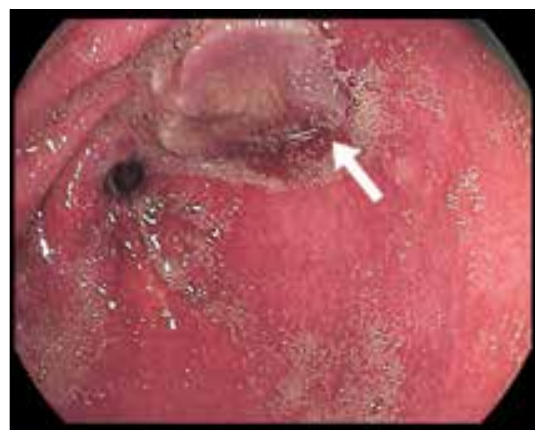

Fig. 3. The gastric antrum. Gastritis is evident, and there is a prepyloric ulcer (arrow). 


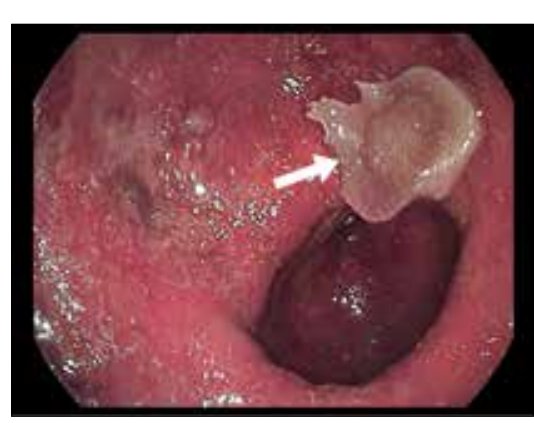

Fig. 4. Prepyloric ulcer (arrow). It shows no signs of recent haemorrhage and has a fibrin-covered base.

slough (Figs 3 and 4); and duodenum - D1 and $\mathrm{D} 2$ duodenitis.

During his stay in hospital the patient experienced no further haematemesis. Melaena was noted for 2 days after admission and then resolved. The left arm swelling resolved, and he remained haemodynamically stable.

The results of blood tests on arrival at Ngwelezane Hospital at $07 \mathrm{~h} 00$ were as follows: $\mathrm{Hb} 6.8 \mathrm{~g} / \mathrm{dL}$, white cell count $15.58 \times 10^{9} / \mathrm{L}$, platelets $205 \times 10^{9} / \mathrm{L}$, sodium $136 \mathrm{mmol} / \mathrm{L}$, potassium $4.4 \mathrm{mmol} / \mathrm{L}$, urea $6.9 \mathrm{mmol} / \mathrm{L}$ and INR 1.19. Liver function was normal.
The patient received two further units of packed red blood cells and oral omeprazole. He was discharged from hospital after 3 days with an $\mathrm{Hb}$ of $8.6 \mathrm{~g} / \mathrm{dL}$.

\section{Discussion}

This case illustrates a number of interesting aspects of the management of snakebite. Firstly, it is a dramatic presentation of a haematoxic snakebite. A bite from a boomslang produces a consumptive coagulopathy with onset between 6 and 36 hours after envenomation. ${ }^{[1]}$ In particular, a profound drop in fibrinogen levels develops. ${ }^{[1,2]}$ This is one of the indications for the use of cryoprecipitate. ${ }^{[2]}$ Since this product was not available at the base hospital, and it was not possible to measure the fibrinogen level there, FDP was a good choice.

Of note is that the use of polyvalent antivenom is not indicated in boomslang bite; instead boomslang antivenom should be used. ${ }^{[1,3]}$ Since this was not available, polyvalent antivenom was given. The patient nevertheless experienced a remarkable reversal of bleeding symptoms and thrombocytopenia, the platelet count climbing from 2 to $205 \times 10^{9} / \mathrm{L}$ in less than 24 hours. It could be argued that the initial platelet count was spurious, but the presence of diffuse oesophageal petechiae would contradict this.

It is also possible that the snake was wrongly identified. Puff adder (Bitis arietans) bites are far more common than boomslang bites, and may also result in bleeding. ${ }^{[3]}$ In support of this was the amount of swelling, which was more than would be expected from a boomslang bite, ${ }^{[1-3]}$ and the fact that the polyvalent antivenom was so effective.

Also of note is that the patient had another risk factor for the development of an upper gastrointestinal (GI) bleed, namely chronic heavy alcohol consumption. This is likely to have contributed to his gastric ulcer, and possibly his gastritis as well. The actual source of his upper GI bleed was probably the severe haemorrhagic gastritis, since petechial haemorrhages do not bleed and the gastric ulcer showed no evidence of a recent bleed (Forrest III).

\footnotetext{
1. Müller GJ, Modler H, Wium CA, Veale DJH, Marks CJ. Snake bite in southern Africa: Diagnosis and management. CME 2012;30(10):362-381.

2. Ashe S, Blaylock R, Chisale MGP, et al. Guidelines for the Prevention and Clinical Management of Snakebite in Africa. Brazzaville: World Health Organization, Regional Office for Africa, 2010.

3. Blaylock RS. The identification and syndromic management of snakebite in South Africa. S Afr Fam Pract 2005;47(9):48-53.
}

Accepted 19 January 2016. 